\title{
¿Y el título para cuándo? El proceso de regularización del barrio Virgen Misionera
}

\author{
Waiting for the deeds. The regularization process \\ of the Virgen Misionera Neighbourhood
}

Tomás Alejandro Guevara

\section{Resumen}

Este artículo presenta resultados preliminares de un trabajo de investigación en curso sobre políticas habitacionales y urbanas en San Carlos de Bariloche. Reconstruye el proceso de regularización del barrio popular de origen informal Virgen Misionera. Los habitantes están arraigados en el lugar y el barrio está completamente consolidado, pero todavía persisten problemas y conflictos vinculados a la titularidad de las tierras con los propietarios originales y emergen conflictos vinculados a la consolidación del barrio. En un contexto donde los precios de los terrenos se dispararon en los últimos quince años, el artículo reflexiona sobre los límites de las estrategias de regularización utilizadas en nuestro país y plantea la necesidad de reformular el contenido y el alcance del derecho de propiedad.

Palabras clave: regularización; lote abandonado; derecho de propiedad; asentamientos informales; políticas habitacionales.

\begin{abstract}
This paper presents preliminary results of an ongoing research on housing and urban policies in San Carlos de Bariloche, Argentina. It reviews the regularization process of an informal settlement called Virgen Misionera. The neighborhood and its population are fully consolidated, but there are still problems and conflicts related to the ownership of land plots and, thus, conflicts related to the urban consolidation of the settlement emerge. In a context where land prices soared in the last fifteen years, the article reflects on the limits of the regularization strategies used in Argentina and raises the need to reformulate the content and scope of property right.
\end{abstract}

Keywords: regularization; abandoned plot; property right; informal settlements; housing policies. 


\section{Introducción}

Esta ponencia presenta resultados preliminares de un trabajo de investigación en curso sobre políticas habitacionales y urbanas y procesos de producción del hábitat en la ciudad de San Carlos de Bariloche. Reconstruye el proceso de regularización protagonizado por un barrio popular de origen informal en San Carlos de Bariloche, denominado Virgen Misionera, ubicado a la altura del kilómetro 7,5 de la Avenida Pioneros, en la Delegación Cerro Otto de la zona oeste del ejido urbano de la ciudad. Junto a Barrio Parque Villa Llanquihue en el km 24,5 de la Avenida Exequiel Bustillo, Don Bosco en el km 19 de la misma avenida, ambos de la Delegación Lago Moreno, y otros pocos más, son de los escasos barrios populares que rompen con el profundo patrón de segregación socioresidencial imperante en la ciudad, que relega a la zona denominada "El Alto" en la Delegación Sur y a la zona del arroyo Ñireco a los barrios populares y a los conjuntos de viviendas de interés social.

Si bien los habitantes más antiguos del barrio, que vivían de una forma semi rural con un uso extensivo de la tierra, criando animales y aves de corral, se localizaron en la zona hace más de 60 años, antes de que se loteara gran parte de la tierra suburbana de la zona oeste, el proceso de regularización se inició recién décadas después, durante los años ochenta y aún hoy se encuentra inconcluso. Durante estos años, el barrio alternó momentos de alta y baja en la conflictividad vinculada a la tierra, enfrentando periódicamente amenazadas de desalojo y soportando la animosidad y estigmatización de una gran parte de la sociedad barilochense.
Jugó un rol central en la organización de base de los habitantes y en el impulso del proceso de regularización el Equipo Pastoral de Tierras (EPT) ligado a la labor pastoral del Cura Juvenal Curulef y posteriormente incorporado como uno de los ejes de trabajo de la Fundación Gente Nueva, que surgió como un desprendimiento de dicho trabajo pastoral. Para llevar adelante la regularización del barrio, el EPT apeló a diferentes estrategias, entre otras: compra directa a los propietarios, impulso a juicios de prescripción adquisitiva (usucapión), articulación con el Estado para negociar condonación de deudas de otros inmuebles a cambio de la propiedad de lotes ocupados, gestión de recursos de programas nacionales de regularización de nivel nacional y, recientemente, implementación de la operatoria de regularización dominial establecida por la Ley Nacional 24.374 de 1994 conocida como "Pierri". Los habitantes están arraigados en el lugar y el barrio está completamente consolidado en términos urbanísticos, pero todavía persisten problemas y conflictos vinculados a la titularidad de las tierras con los propietarios originales, los cuales reclaman sus derechos de propiedad sobre inmuebles que en muchos casos abandonaron durante años.

También emergen nuevos conflictos vinculados a la consolidación y densificación del barrio, como son: la presión demográfica de las segundas y terceras generaciones de habitantes que demandan acceso al suelo para construir sus viviendas, o lo hacen en el mismo lote que sus padres, sobrecargando la infraestructura y el espacio, que se encuentra en un entorno natural delicado; la calidad del espacio público y el equipamiento, por los 
conflictos que suscitan intentos de ocupación de espacios que cumplen una función comunitaria, como ocurrió con la cancha de fútbol o la plaza; la oposición frente a la posibilidad de nuevas tomas de terrenos, estigmatizando así los viejos ocupantes a los nuevos ocupantes; conflictos con comunidades de pueblo originarios que demandan restitución de tierras que le pertenecerían a sus comunidades, etc.

La relativa abundancia de tierra de expansión en la ciudad y el abandono por parte de los propietarios permitió durante años que los procesos de regularización pudieran avanzar de forma más o menos exitosa. No obstante, en los últimos quince años, en un contexto donde los precios de los terrenos se dispararon, especialmente después de la devaluación de 2002, empezaron a aparecer nuevos conflictos vinculados a la voluntad de propietarios o herederos de recuperar la posesión de sus terrenos, que ahora tienen un extraordinario valor. El desfasaje de los precios de los terrenos con el ingreso promedio de los sectores populares, incluso medios, vuelve prácticamente imposible cualquier arreglo de tipo económico que posibilite la regularización de la posesión.

En este marco, en 2000, el Gobierno Provincial adhirió a través de la Ley Provincial 3.396 al régimen de regularización de ocupaciones establecido por la Ley Nacional 24.374. Lo mismo hizo la Municipalidad de San Carlos de Bariloche, a través de la Ordenanza 1.283 de 2003. Pero recién a fines de 2013, la autoridad de aplicación, el Instituto de Planeamiento y Promoción de la Vivienda de Río Negro (IPPV), firmó un convenio con el Instituto Municipal de Tierras y Vivienda para el Hábitat
Social (IMTVHS) de San Carlos de Bariloche para la aplicación de la operatoria en la ciudad, que se puso en marcha en 2014 en algunos barrios, Virgen Misionera entre ellos. Si bien existe una enorme expectativa sobre la capacidad de esta operatoria para saldar una histórica deuda con miles de habitantes de barrios populares de origen informal de Bariloche, una mirada más desapasionada muestra que existe una proporción importante de estos terrenos que no podrán ser regularizados por esta vía, ya sea por la oposición legal de propietarios 0 herederos, por la fecha de la ocupación de los mismos, o porque por sus características (tamaño, valuación fiscal, etc.) no pueden acogerse al mencionado régimen. Es previsible entonces que la problemática persista y se hace necesario buscar otras alternativas de resolución de conflictos.

El presente artículo reflexiona sobre los límites de las estrategias de regularización dominial utilizadas en nuestro país, a partir del caso del barrio Virgen Misionera de San Carlos de Bariloche, y plantea la necesidad de reformular el contenido y el alcance del derecho de propiedad, en vistas a poner de relieve su función social, su carácter de bien de uso antes que de cambio y el derecho humano básico fundamental a su acceso.

\section{El proceso de urbanización de Bariloche}

El proceso de urbanización de la ciudad de San Carlos de Bariloche comparte algunos rasgos con muchas otras ciudades de perfil turístico en nuestro país. ${ }^{1}$ La expansión urbana de la 
ciudad estuvo estrechamente vinculada a la masificación del turismo, especialmente entre las décadas de 1940 y 1970 . Algunos de los loteos más viejos incluso datan de la década de 1930, cuando la gestión de la Dirección de Parques Nacionales, creada en 1934 por la Ley 12.103, impulsó la creación de villas turísticas para financiar obras de infraestructura que modernizarían la aldea de montaña. La llegada del ferrocarril en 1934, la inauguración del aeropuerto en 1966 y la conectividad por ruta asfaltada en 1968 fueron condiciones fundamentales de esta masificación. Durante esta etapa, se produjo un proceso acelerado de loteo de las tierras adjudicadas en el período previo, sin tener en cuenta la dotación de infraestructura, la demanda habitacional local o criterios mínimos de planificación urbana. Abaleron (2001) estima más de 3.900 hectáreas loteadas, principalmente en áreas boscosas. Esta política de laissez faire determinó una expansión acelerada del ejido urbano, de bajas densidades y bajo nivel de consolidación.

Así, tempranamente se subdividió una gran parte de las tierras disponibles para la expansión urbana. La regulación era muy laxa en esa época, habilitaba la subdivisión sin mayores requisitos que la agrimensura y la presentación de los planos, favoreciendo la subdivisión especulativa de tierras, desligada de las necesidades de desarrollo local. Este tipo de loteo significó enormes beneficios para los propietarios originales y para las sociedades comerciales que fueron surgiendo para la subdivisión y comercialización de esta tierra. De hecho, la inversión requerida era tan baja que en muchos casos la sociedad comercial se liquidaba antes de terminar de vender la totalidad de los lotes, porque el costo de mantener funcionando la sociedad era mayor que el beneficio marginal de terminar de vender los lotes remanentes (Paolinelli, Guevara y Oglietti, 2014). Por otro lado, la comercialización se hacía muchas veces en los grandes centros urbanos donde estaban los potenciales compradores de lotes en ciudades turísticas, los cuáles ni siquiera viajaban para conocer la ubicación del mismo, lo cual sólo se explica por un contexto donde todavía la tierra tenía valores relativamente bajos en relación a los ingresos medios de la población y existía la posibilidad de pagar a plazos. ${ }^{2}$ En muchos casos, también, los títulos de propiedad no estaban del todo saneados, existiendo numerosos casos donde se vendieron dos veces lo mismo por diferentes promotores, se vendían propiedades con títulos falsos o imperfectos, etc. Pasaron muchos años antes de que los propietarios fueran a tomar efectiva posesión del lote, a veces no lo hicieron nunca, o al menos nunca invirtieron en su desarrollo. Como consecuencia de este proceso caótico y especulativo, en pocos años se lotearon miles de hectáreas de suelo de expansión, sin ningún tipo de correlato con las necesidades habitacionales de la ciudad, especialmente en la zona oeste del ejido urbano. Entre 1960 y 1980 se produce un crecimiento demográfico acelerado de la ciudad, en gran medida explicado por la migración de población que era atraída por el desarrollo turístico: en 1980, la población alcanzó los 51.268, convirtiéndose en la ciudad más poblada de Río Negro. Si bien la tasa de crecimiento demográfico se fue reduciendo progresivamente, en 2010 registró algo más de 112.000 habitantes, lo que implicó casi multiplicar por cuatro la población al cabo de cuatro décadas, convirtiéndose en la tercera 
Mapa 1 - Ejido Urbano de San Carlos de Bariloche

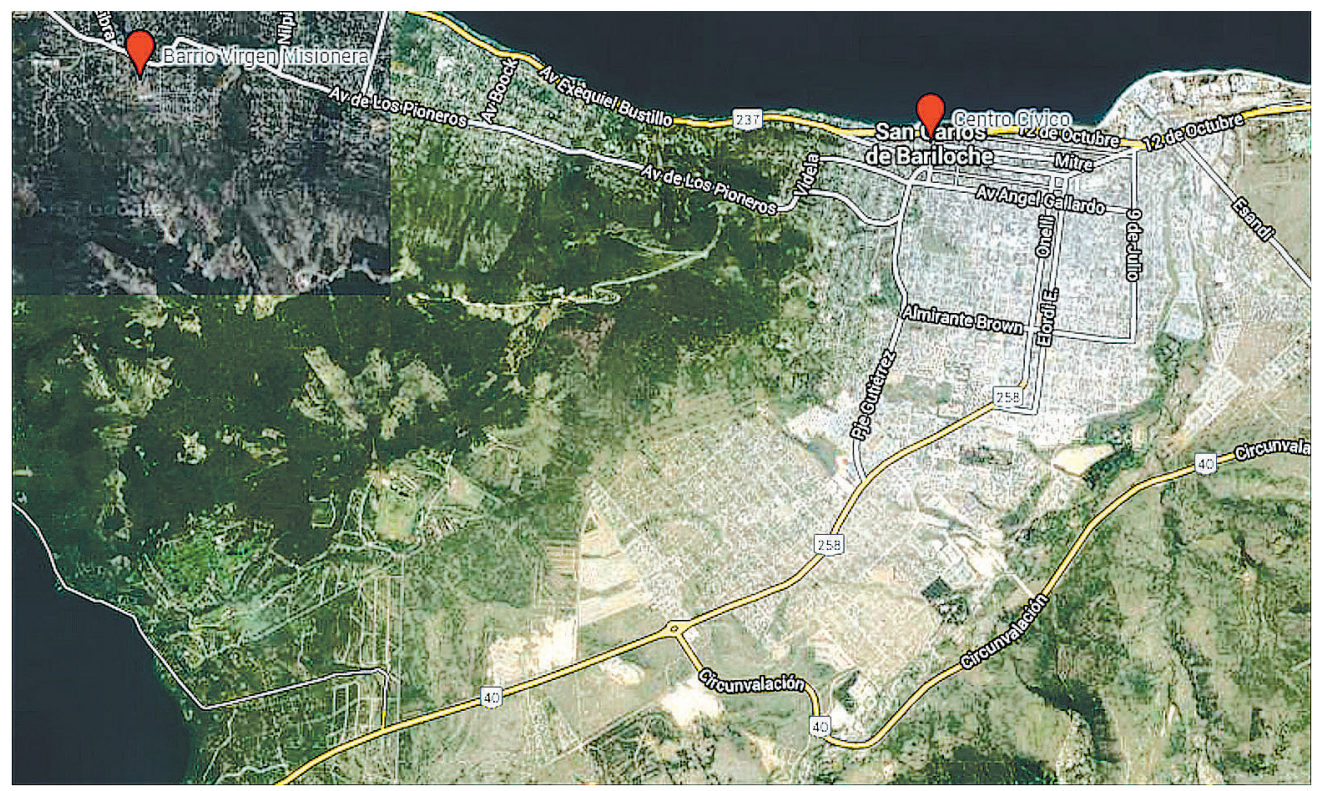

Fuente: Elaboración propia.

ciudad más poblada de la región patagónica. No obstante, gran parte de esta población se fue localizando en el eje de expansión sur, donde se localizaron los barrios populares.

Esta expansión tan acelerada y con un gran componente especulativo en el mercado de suelo determinó muchos problemas en términos de la consolidación de la trama urbana. El primero de ellos, la dotación de servicios públicos. Rápidamente, la extensión del ejido urbano aumento hasta convertirse en uno de los más grandes del país, con más de 27 mil hectáreas. Es sabido que el costo de las infraestructuras de red aumenta exponencialmente con la distancia. Asimismo, cuando la densidad es muy baja, se vuelve económicamente inviable esta expansión. Pese a esto, la existencia de grandes emprendimientos turísticos a lo largo del eje oeste, en la costa del Lago Nahuel Huapi -especialmente el Hotel Llao Llao en el km 24,5 de la Avenida Bustillo construido a fines de la década de 1930determinó que fuera del interés del Estado la expansión de los servicios, favoreciendo la consolidación progresiva la trama urbana en espacios intersticiales. Como resultado, la Municipalidad de San Carlos de Bariloche tiene una limitación estructural para atender de forma cabal la totalidad del ejido urbano bajo su jurisdicción. En algunas situaciones, lo propietarios ni siquiera se hicieron cargo de sus obligaciones fiscales, generando un problema presupuestario importante para el gobierno 
local. La expansión urbana descontrolada encarecía la prestación de servicios sin que siquiera aumentara de manera correspondiente la base fiscal. Esto fue paliado parcialmente por medio de la organización autogestiva de los vecinos de los barrios que fueron generando soluciones para la dotación de agua potable, tanques comunitarios, empresas de potabilización, tendido de cloacas y otras obras de infraestructura. Estos procesos organizativos fueron el germen de la institucionalización a fines de la década de 1980 de las actuales Juntas Vecinales, que ya son más de cien en toda la ciudad.

Uno de los principales problemas que generó el proceso de urbanización descripto tiene que ver con la existencia durante años, incluso décadas, de lotes baldíos que no eran construidos por sus dueños. Incluso, una parte no poco significativa de estos lotes estaban en notorio estado de abandono, sin cerco, sin desmalezar (Paolinelli, Guevara y Oglietti, 2014). Estos lotes abandonados fueron objeto de ocupaciones en muchos casos, antes o después de ser loteados, dando origen a barrios enteros a lo largo del ejido de Bariloche.

Algunos de estos barrios emprendieron procesos de regularización dominial y urbanística, en general, por iniciativa de la población local y de sus organizaciones de base. La municipalidad no tuvo un accionar relevante en esta materia durante muchos años. En el mejor de los casos, optó por la omisión. En el peor de los casos, cuando los barrios se localizaban en zonas que eran consideradas "no apropiadas" para la imagen de ciudad turística que se quería promover, se buscó la relocalización compulsiva, como ocurrió por ejemplo con el barrio denominado
"34 hectáreas" producto de la relocalización de al menos 7 barrios que se ubicaban a lo largo de la costa del Lago (Pérez, 2004).

\section{Breve reseña histórica del proceso de urbanización del barrio}

No es objeto de este artículo hacer la historia del barrio Virgen Misionera. ${ }^{3}$ No obstante, es fundamental tener en cuenta algunas coordenadas históricas básicas para comprender el derrotero del proceso de urbanización en el barrio.

Las tierras en las que se asienta eran parte de la herencia de Francisco Pascasio Moreno, Perito de la parte de Argentina en el conflicto limítrofe entre la Argentina y Chile que siguió a la firma del tratado en 1881. Por los servicios prestados a la Nación, Moreno recibió grandes cantidades de tierras en la región. Una parte importante de esa herencia fue donada para constituir lo que hoy es el Parque Nacional Nahuel Huapi, el resto quedó como parte de su herencia particular, incluyendo estas tierras donde se localiza el barrio.

Los primeros pobladores datan al menos de la década de 1940, es decir, previo al proceso de subdivisión de gran parte de la tierra periférica a Bariloche. La población allí asentada vivía en condiciones semi-rurales, prácticamente sin ningún tipo de delimitación de las propiedades (cercos, alambrados), combinando la vivienda con usos productivos destinados al autoabastecimiento (ganado de pastoreo, animales de corral, etc.). Esta situación de origen tiene implicancias 


\section{Mapa 2 - Plano catastral Barrio Virgen Misionera}

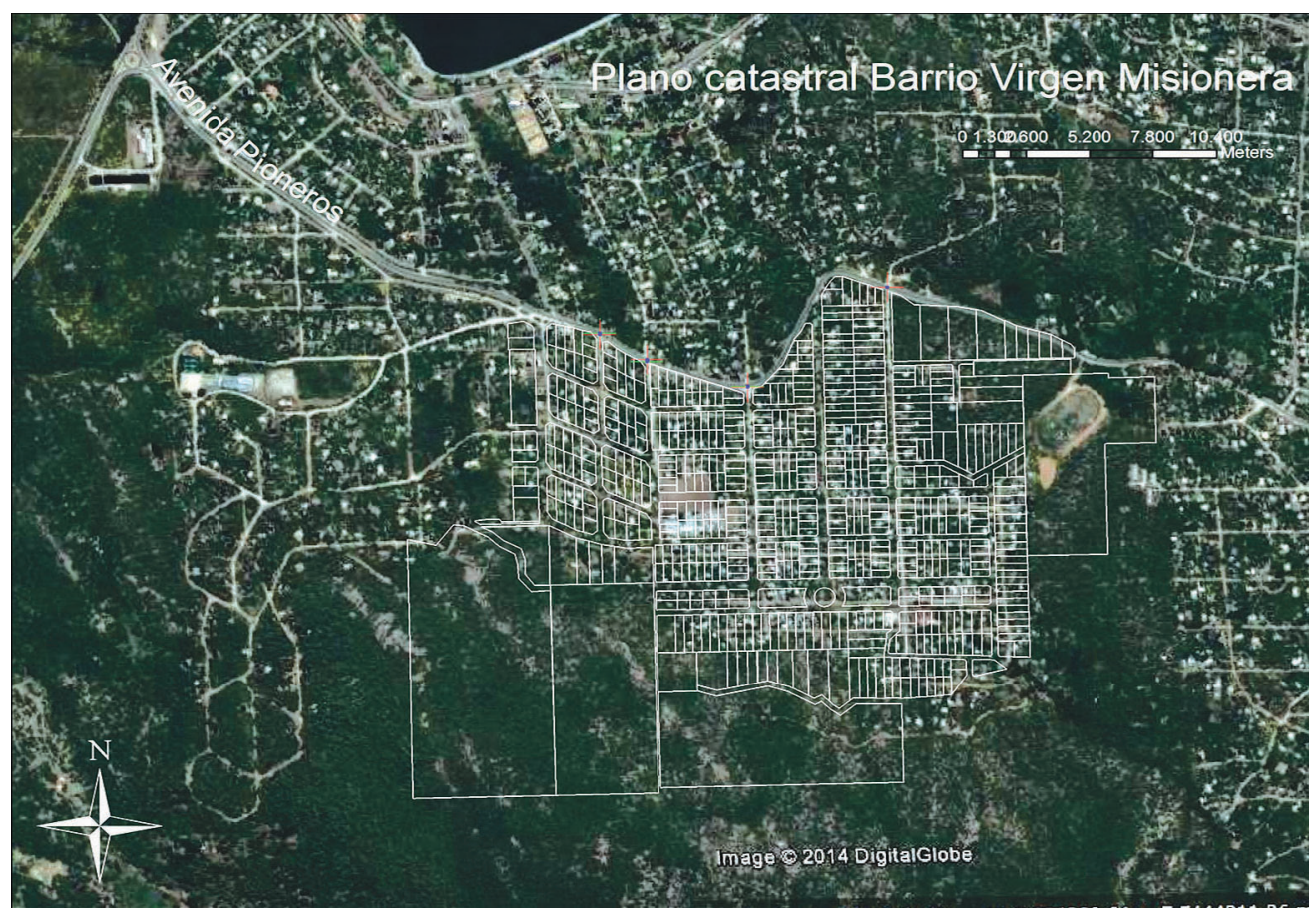

Fuente: Elaboración propia.

importantes para entender los reclamos de la población allí asentada para mantener su residencia en el lugar. Concretamente, una parte de esta población ya vivía en la zona antes de que el loteo en cuestión se realizara, es decir, antes de que los lotes urbanos existieran legalmente como tales. De hecho, en muchos casos, ha sido posible reconstruir a partir de testimonios que la subdivisión y venta de los lotes se hizo obviando que ya había población radicada en el mismo, cuestión que el propietario adquiriente del lote nunca conoció al momento de comprar la propiedad. Esto fue caracterizado por un entrevistado como "ocupaciones negativas", donde "se les superpone una plantilla urbana" a la población preexistente. ${ }^{4}$ Este caso no fue privativo de Virgen Misionera, sino que situaciones similares se vivieron en Villa Don Bosco, Alto Campanario, Villa Llanquihue e incluso Melipal.

Las características del barrio, vinculadas al origen popular de sus habitantes y la localización del mismo, cuestionaba el patrón vigente de segregación socioeconómica que establecía que la zona oeste estuviera destinada a sectores medios-altos y a las actividades vinculadas al turismo, lo que generó rápidamente situaciones conflictivas. 
La población del barrio era estigmatizada en los discursos y las referencias de la población, especialmente por parte de los habitantes de barrios lindantes como Pinar del Lago o Pinar de Festa. Pese a estas representaciones negativas, son innegables y numerosos los vínculos funcionales, especialmente en materia de mercado de trabajo para cubrir actividades de servicios, mantenimiento y reparaciones, que se fueron estableciendo a través de los años entre estos barrios de origen popular ubicados en el eje oeste que colindan con barrios de sectores socioeconómicos medios y altos. ${ }^{5}$ Esta interdependencia lo diferencia situaciones más conflictivas, de menor interrelación, que pueden ser interpretadas más cabalmente en clave de "resistencia", como el caso del Barrio 10 de Diciembre, analizados en otras oportunidades (Guevara y Núñez, 2014 y Núñez y Guevara, 2014). Lo cual no quita que no existiera un conflicto explícito en términos de apropiación y uso del espacio urbano en la ciudad. La situación de no legitimación de la permanencia de los ocupantes en ese lugar, en un contexto de gobiernos autoritarios, dictaduras entre 1966-1973 y 1976-1983, generaron presiones en pos del desalojo del barrio en virtud de su condición de ocupantes. Como consecuencia, rápidamente empezó a surgir algún tipo de organización barrial que buscaba dar respuesta a las demandas de los habitantes del barrio en pos de la seguridad de tenencia de sus viviendas. Pero la no legitimación también persistió en el contexto de recuperación democrática y tuvo que ser objeto de disputa y construcción paciente y sistemática por parte de los habitantes del barrio y sus organizaciones de base.
La organización comunitaria en el barrio tiene uno de sus hitos en la llegada del cura Juvenal Curulef a San Carlos de Bariloche en la década de $1980 .^{6}$ Comenzó su trabajo pastoral en la Parroquia de Virgen de las Nieves en 1981, pero al poco tiempo fue trasladado a la recientemente creada Parroquia de Virgen Misionera, donde concentraría su actividad pastoral hasta su fallecimiento en 2014. En torno al cura párroco se comenzó a congregar un grupo de vecinos de Bariloche, algunos que vivían por la zona y otros que no, otros que trabajaban en el Centro Atómico Bariloche, que comenzaron a desarrollar tareas comunitarias de base, en línea con las posturas al interior de la Iglesia resultantes del Concilio Vaticano II, la Teología de la Liberación, la proliferación de la Comunidades Eclesiales de Base, etc. En el caso de Río Negro, gran parte de esta actividad está ligada a la figura de Miguel Hesayne, obispo de la diócesis de Viedma desde 1975 y con el impulso a la realización del Primer Sínodo Pastoral de la diócesis de Viedma en los años 1983 y 1984. Este grupo pastoral comenzó a desarrollar tareas comunitarias de diversa índole, donde se destacaron las tareas educativas que dieron origen a varias escuelas de gestión social con el correr de los años y a la conformación en 1989 de la Fundación Gente Nueva, una organización no gubernamental que trabaja con diferentes problemáticas sociales. ${ }^{7}$ La acción de este grupo estaba claramente orientada a la inserción territorial en un entorno barrial específico como forma de encarar el trabajo pastoral. ${ }^{8}$

Rápidamente la labor educativa hizo emerger también demandas vinculadas a las necesidades habitacionales de las familias 
ahí asentadas y de familias que empezaban a llegar a la zona buscando donde asentarse. En la década de 1970, por ejemplo, fue importante la migración de origen chilena, especialmente después del golpe militar que derrocó a Salvador Allende. También era importante la llegada de población de comunidades rurales aledañas, expulsadas por la crisis sostenida que atravesaba y sigue atravesando la que era la principal actividad económica, la ganadería ovina. Al calor de este proceso de poblamiento se fueron conformando asambleas en las escuelas como lugar de reunión, donde la problemática del acceso al suelo era una cuestión acuciante. Conceptualizaba su trabajo en términos de propiciar el paso de "lo legítimo a lo legal", apostando a las ventajas positivas de encuadrar legalmente la tenencia de la tierra de los habitantes del barrio. En el documento "La tierra, un bien de todos. Encuadre eclesial" de Curulef (c. 1992), el párroco identifica como una de las causas estructurales de la pobreza en América Latina la falta de acceso a la tierra rural y urbana, heredada del modelo de explotación colonial. De hecho, se plantea cabalmente que el acceso a la tierra es "signo de liberación". En el mismo sentido, señala el camino a transitar el desarrollo de intervenciones territoriales concretas por parte de los grupos pastorales, a través de las comunidades eclesiales de base, planteando una iglesia "al servicio de las organizaciones populares", alineándose con las doctrina social de la iglesia y con las orientaciones derivadas del Concilio Vaticano II (1962-1965) y de las reuniones de Medellín (1968) y Puebla (1979).

A raíz de esta creciente demanda ligada a la problemática de la tierra terminó conformándose un Equipo Pastoral de Tierras
(EPT) que jugó un rol muy relevante en la ocupación concertada del barrio y en el impulso a los procesos de regularización que se iniciaron desde la década de 1980. Posteriormente, cuando se conforma en la década de 1980 la Fundación Gente Nueva, el EPT pasó a formar parte de la misma, como uno de sus principales ejes de acción, si bien mantuvo una relación estrecha con la Parroquia de Curulef.

Desde la creación de la Fundación Gente Nueva, el proceso de urbanización del barrio siguió su derrotero habitual de los barrios populares de: a. expansión, en la medida que se iban ocupando los lotes vacantes; $b$. consolidación, con el mejoramiento progresivo de las viviendas por parte de las familias, la concreción de las redes de servicios y equipamiento colectivo; y c. densificación, con la temprana aparición de segundas, terceras y más viviendas en algunos lotes, tanto para responder a la demanda habitacional de la propia familia, como estrategia para la obtención de una renta a través del alquiler informal de las mismas (Di Virgilio, Arqueros y Guevara, 2011). Asimismo, la dotación de servicios e infraestructura del barrio fue extendiéndose y completándose a lo largo de los años, con un fuerte componente de organización comunitaria, como sucedió en gran parte de la ciudad. En la actualidad el barrio no cuenta todavía con la red de cloacas. En 2011, según un relevamiento realizado por el EPT, casi el $37 \%$ de los hogares identificaba como la primera necesidad del barrio la extensión de la red de cloacas, ${ }^{9}$ seguida de las tareas de mantenimiento y pavimentación de las arterias viales (30\%).

En sus comienzos, el rol del EPT se limitó a organizar y viabilizar las ocupaciones 
de lotes baldíos, privilegiando aquellos que se encontraran en condiciones de abandono, especialmente aquellos lotes que tenían deuda acumulada de impuestos y tasas con la Provincia y el Municipio. Para ello, fue central el desarrollo de diferentes estrategias para ir "limpiando" los terrenos que podían ser ocupados o no. No obstante, como siempre aclaran los entrevistados, la ocupación siempre fue una decisión individual del ocupante, "por su cuenta y cargo", según la expresión de un miembro del equipo. El EPT se limitaba a asesorarlo en esa decisión para tratar de evitar la mayor cantidad de problemas que pudieran surgir de esta situación y a servir de mediador frente a los propietarios en los casos en que estos podían ser encontrados. Pese a esto, toda la labor realizada en torno al grupo pastoral liderado por el cura Curulef en el barrio le valió la oposición de muchos sectores sociales del barrio y de la ciudad, que lo vinculaban estrechamente a los sectores populares como una forma de estigmatizarlo, mientras que el cura hacía de esto una bandera y su principal virtud. Lo que se planteaba era un conflicto social en torno de la apropiación y el uso del espacio urbano por parte de diferentes sectores sociales y la legitimidad de cada uno para localizarse en determinados puntos de la ciudad (Herzer, Gil y de Anso, 2012).

Durante la década de 1980 y 1990 comenzó el trabajo orientado a regularizar las situaciones de ocupaciones de hecho. En primer lugar, porque empezaron a aparecer propietarios registrales de los lotes ocupados que querían recuperar la posesión de los lotes. En segundo lugar, porque la aparición de estos propietarios comenzó a generar la inquietud del resto de familias en situación de ocupación irregular sobre la necesidad de regularizar de alguna forma la tenencia de los mismos. Es necesario aclarar que si bien desde que se conforma el EPT el precio de los lotes no cesó de aumentar, todavía durante la década de 1980 e incluso durante la década de 1990 los precios del mercado inmobiliario guardaban cierta proporción con el ingreso medio de los habitantes de la ciudad, lo que no los volvía completamente inaccesibles. De hecho, en gran medida el problema era de financiamiento, por lo que el EPT funcionó muchas veces como un intermediario que viabilizaba las compras por parte de los ocupantes a los propietarios. Incluso el EPT adquirió lotes que no estaban ocupados y los fue adjudicando en procesos asamblearios en función de una lista de espera que se iba conformando. No obstante, desde la devaluación de 2002, la aceleración de los precios del mercado inmobiliario generó un desfasaje por completo en estas variables, que explica en gran medida el renovado interés de los propietarios en años recientes por recuperar sus propiedades y la casi total imposibilidad por parte de los ocupantes de negociar condiciones de compraventa accesibles económicamente en función de sus ingresos.

El EPT se dio varias estrategias para propiciar la regularización dominial de los lotes ocupados durante las primeras dos décadas de su funcionamiento. En general, su rol se limitó al de intermediadora y organizadora de las demandas. Básicamente, se planteaba intermediar en una negociación directa con el dueño, en pos de habilitar la compra del lote por parte de los ocupantes. Es necesario tener en cuenta que dado el perfil social del EPT, con gran cantidad de profesionales, el mismo tenía mayor capacidad para movilizar redes 
y recursos (Di Virgilio, 2011) que facilitaran tanto la relación con las diferentes instancias del poder ejecutivo, pero también del poder judicial, acceso a escribanos, abogados, etc.

La respuesta por parte de los propietarios fueron muy variables. En algún caso, el EPT llegó a conseguir la cesión sin cargo del lote por parte del propietario, cuando este percibía que la recuperación era inviable. En otros casos, el EPT compraba lotes que después eran revendidos con facilidades a los ocupantes, oficiando de intermediador. A veces, se limitaba a servir de mediador en las negociaciones que se hacían entre privados.

Las respuestas de los mismos vecinos del barrio también fueron variables. Fue marcada la crítica y oposición de los vecinos "legales", es decir, aquellos que contaban con los títulos de propiedad en regla. Este sector estuvo durante mucho tiempo nucleado alrededor de la Junta Vecinal Virgen Misionera y fue un activo opositor a la política de regularización impulsada por el EPT. Durante años fue uno de los principales actores que propició la actuación legal de los propietarios en pos del desalojo de ocupantes. Incluso llegaba al extremo de ocuparse de contactarlos cuando vivían en otras localidades y ofrecerse a ser custodio de los mismos en su ausencia, según los testimonios. De hecho, una entrevistada relató concretamente cómo el Municipio había impulsado durante la década de 1990 la conformación de la Junta Vecinal Virgen Misionera en oposición al proceso de organización de base del barrio, promoviendo su estigmatización y desalojo. ${ }^{10}$ En los últimos años, no obstante, ante un cambio en la conducción de la entidad, la Junta Vecinal jugó un rol más positivo y favorable al proceso, que permitió fortalecer la legitimidad en el barrio. Lo mismo sucedió con muchas otras organizaciones que fueron naciendo al calor del proceso de organización comunitaria que tenía como una de sus referencias fuertes a la parroquia, como el Club Social y Deportivo Arco Iris o la radio comunitaria. La misma heterogeneidad puede encontrarse entre las diferentes generaciones de ocupantes, llegando al extremo de que el EPT, según testimonios de sus miembros, reciba en la actualidad críticas de algunos habitantes de larga data por no haber reservado tierra para sus hijos y nietos y haberla cedido a gente de afuera del barrio, con una mención particular para con los migrantes chilenos recientes, mostrando algunos de los clivajes conflictos dentro del grupo social que conforma el barrio.

No obstante este rol de mediador y organizador, la labor del EPT nunca descuidó la interpelación a los diferentes niveles del Estado y en numerosas oportunidades cuestionó la orientación de las políticas públicas que no daban cuenta de manera cabal de la problemática acuciante del acceso al suelo. Tampoco partían de un diagnóstico inocente de la problemática, sino que no dudaban en señalar el carácter estructural del problema habitacional en la sociedad barilochense y que afectaba de manera predominante a los sectores más vulnerables.

En la actualidad, de un total de alrededor de 570 lotes identificados catastralmente en el barrio, prácticamente la mitad de los lotes (42\%) han recibido algún tipo de intervención por parte del EPT (ver Tabla 1). ${ }^{11}$ De este total, sólo 25 han sido finalmente escriturados a nombre de sus actuales ocupantes. Este porcentaje tan reducido de regularización 
dominial definitiva, después de más de 25 años de intervención por parte de la organización, es un primer indicador que nos muestra de la complejidad y los obstáculos jurídicoinstitucionales con los que se enfrente este tipo proceso.

Existe un total de 125 lotes que han iniciado o podrían iniciar el trámite de regularización previsto por la Ley Pierri (mientras no se encuentren incompatibilidades adicionales), lo que representa un universo de 180 hogares; mientras que 24 están excluidos de la misma de entrada porque su ocupación data de una fecha posterior a 2006, una de las restricciones que fija la Ley 3.396. Algo más de 50 lotes están en condiciones de ser escriturados, ya sea por tener boleto de compra venta o por estar enmarcado en la operatoria prevista por la Ordenanza 1120-CM-2001.
Dentro del universo de lotes ocupados, había un conjunto de alrededor de 50 lotes que eran propiedad de la firma El Sol S.A., cuyo principal accionista era Vinelli, un conocido loteador y agente inmobiliario del país, con gran actuación en la ciudad de Bariloche y en la costa atlántica de Buenos Aires. Este conjunto de lotes requirió de una negociación especial, por la concentración de la propiedad en un sólo propietario, lo cual permitía solucionar el problema de decenas de familias de una sola vez. Esto permitió ordenar la negociación, pero no por ello la hizo más fácil, porque se trataba de un experimentado agente inmobiliario. La Ordenanza 1120-CM-2001 finalmente aprobó un convenio de compensación de deudas municipales con la firma El Sol S.A. Por este convenio, el Municipio adquirió la propiedad de 51 lotes que fueron posteriormente vendidos

Tabla 1 - Universo de actuación del EPT, estado de situación y proyección de trabajo

\begin{tabular}{l|c|c}
\hline & N & $\%$ \\
\hline Cantidad de lotes en catastro & 569 & 100,0 \\
Cantidad de lotes con intervención EPT & 239 & 42,0 \\
Lotes que podrían iniciar trámite Pierri & 87 & 15,3 \\
Lotes para escriturar Ordenanza 1120-CM-01 & 39 & 6,9 \\
Lotes que iniciaron trámite Pierri & 38 & 6,7 \\
Lotes escriturados & 25 & 4,4 \\
Lotes ocupados recientemente (excluidos Pierri) & 24 & 4,2 \\
Lotes en condiciones de escriturar & 13 & 2,3 \\
Lotes para prescripción administrativa & 6 & 1,1 \\
Lotes con reclamos de comunidades originarias & 4 & 0,7 \\
\hline
\end{tabular}

Fuente: Elaboración propia del autor en base a datos del EPT. 
en cuotas a los ocupantes mediante boleto de compra-venta aprobado en la misma ordenanza. Algunos de estos lotes ya fueron completamente pagados y están pendientes de escrituración (8 lotes), otros tienen cuotas pendientes (18 lotes, otros tienen problemas de mensura y/o subdivisión, pero muy pocos han logrado escriturar definitivamente el lote (4 lotes). La operatoria, a su vez, era incorporada en la Ley Provincial 3.370 que establece una escrituración de bajo costo para este tipo de situaciones.

\section{Políticas de regularización de barrios populares de origen informal en Bariloche ${ }^{12}$}

Clichevsky (2003), distingue tres tipos de políticas de regularización: 1) aquellas que tienen por objetivo sanear la situación dominial; 2) aquellas que tienen por objetivo sanear la situación urbano-ambiental y 3) las integrales que articulan i. y ii. Según esta investigadora, las experiencias de políticas de regularización integral han sido escasas. Generalmente, las políticas de regularización se implementaron de manera desarticulada, siendo mucho más extendidas las políticas de tipo i. Ello se debió a que este tipo de intervenciones es menos costoso, tiene mayor visibilidad en términos políticos y ha recibido una fuerte promoción de parte de algunos organismos internacionales por sus supuestos efectos multiplicadores.

Las políticas de regularización surgieron en la década de 1960 especialmente en aquellos países donde la normativa urbana muy rígida había generado situaciones de informalidad.
Esta regularización era tanto dominial como urbana, pero la falta de presupuesto la dejó limitada a lo dominial. México y Perú son dos de los países pioneros en la materia, ya en la década de 1960 y 1970. Sin embargo, la dinamización de estas políticas se produce durante la década de 1990, impulsadas por organismos internacionales que, influidos por la tesis de Hernando de Soto (De Soto, Ghersi y Ghibellini, 1986), entendieron que la regularización dominial tendría por sí misma efectos beneficiosos en las condiciones de vida de la población, al promover su inserción social, movilizar capitales y facilitar la integración en otras esferas tales como la laboral, educativa, etc. No obstante, los procesos no necesariamente han llegado a buen puerto y tampoco han provocado los efectos previstos. En numerosas situaciones que lograron ser regularizadas se desarrollaron nuevos procesos de informalización asociados a problemas de sucesión, de subdivisión, de venta y/o alquiler en el mercado inmobiliario informal (Ward et al., 2011).

En la década de 1990 la situación de la pobreza urbana con respecto al acceso al suelo se agrava notablemente. En este contexto, los procesos de reforma del Estado y de reestructuración económica que caracterizaron a esta década impactaron fuertemente en el funcionamiento del mercado de suelo urbano y generan cambios en las políticas de regularización implementadas. Desde entonces, el paradigma de políticas habitacionales se traslada de las políticas de vivienda tradicional, a los lotes con servicio y posteriormente a la legalización y mejoramiento de barrios. Las políticas de regularización dominial han avanzado mucho 
más sobre tierras públicas, que sobre tierras privadas, donde el Estado debe primero expropiar o ser mediador en una negociación.

En Argentina la regularización es un proceso reciente a nivel nacional, aunque algunos municipios la han implementado desde hace más de 20 años. La reforma constitucional de 1994 no significó un avance en términos de acceso al suelo, a diferencia de las últimas enmiendas en otros países de la región, con excepción de algunos derechos vinculados a las problemáticas de los pueblos originarios y ambientales. ${ }^{13}$ La Constitución de la República Argentina (CA) no establece la función social de la propiedad, sino que en su artículo 17 establece la inviolabilidad de la propiedad privada. No obstante, el artículo 14 bis establece el derecho a una vivienda digna y el artículo 41 establece el derecho a un ambiente sano. Esta conjunción de derechos, que muchas veces colisionan en realidad, debe ser resuelta políticamente por las autoridades competentes (tanto el legislativo como el ejecutivo) o en última instancia por el poder judicial. El Código Civil regula todo lo atinente a la propiedad de la tierra y de la vivienda, pero lo hace enmarcándose en los principios constitucionales de la inviolabilidad de la propiedad. Esto genera grandes obstáculos en materia de regularización dominial, porque en general tiende a primar el derecho de propiedad irrestricto, por sobre otras consideraciones, como la función social de la propiedad, que permitiría problematizar por qué un terreno apto para urbanizar está siendo retenido por su dueño, por poner sólo un ejemplo.

En este marco, es notoria la ausencia de una política de regularización unívoca a nivel nacional, los pocos intentos de articular una política integral y universal fracasaron y se recayó una y otra vez en la sanción de normativa específica para cada caso, segmentando las soluciones y vulnerando el principio de igualdad ante la ley de los habitantes de las diferentes urbanizaciones informales. Esta situación expresa, en parte, un cierto consenso del sistema político acerca de no cuestionar las relaciones de propiedad y el acceso a la tierra y a la vivienda, poniendo a la propiedad privada por encima de los derechos sociales, económicos y culturales de las familias de menores ingresos y no reconociendo que existe una pugna entre dos derechos legítimos que debe ser procesada por instituciones adecuadas.

En el marco de la reforma del Estado y de la aplicación de las medidas de corte neoliberal durante la década de 1990, se sancionaron algunas normativas que habilitaron mecanismos de transferencia y regularización de tierras para el hábitat de sectores populares: - En 1989, la Ley de Emergencia Económica ${ }^{\circ}$ 23.697 habilitó la posibilidad de que el Estado Nacional transfiera a privados la propiedad de tierras fiscales que previamente fueran declaradas innecesarias para la gestión.

- De manera similar, el Decreto 1.001 de 1990, habilitó la transferencia de las tierras fiscales sobre las que se asentaban las villas de emergencia de la Ciudad de Buenos Aires. El Decreto 2.411 de 1990 extiende este mismo criterio para todas las villas del Gran Buenos Aires.

- Asimismo, la Ley 23.967 de 1991 transfiere tierras en propiedad del Estado Nacional que se hallen ocupadas por viviendas permanentes y que sean innecesarias para el cumplimiento 
de su gestión, a las Provincias y Municipios para su posterior venta o incorporación a planes sociales de vivienda social.

- La Ley 24.374 de 1994, conocida como "Ley Pierri" habilitó la transferencia de tierras privadas a sus ocupantes reales. El objetivo era acortar los plazos administrativos del instituto jurídico de la posesión veinteañal o usucapión del Código Civil. Se constituye en una suerte de usucapión pero que cursa en sede administrativa, que tiene las ventajas de reducir los plazos de 20 a 10 años para el perfeccionamiento de las actas-escrituras y reducir notablemente los costos en comparación con juicio de usucapión. Esto no obsta para que, en caso de que exista oposición por parte del propietario, el trámite se suspenda y en todo caso deba resolverse en sede judicial. El único costo que tiene la operatoria es una contribución del $1 \%$ del valor fiscal de los inmuebles, con la finalidad de dotar de financiamiento a la misma.

- Otra de las normativas relevantes en términos de regularización es el instituto de la expropiación, que si bien fue originalmente concebida para contar con suelo para la construcción de infraestructura y equipamiento colectivo, fue adaptándose también para su implementación en urbanizaciones informales. La expropiación garantiza la ocupación y elimina el riesgo de desalojo, sin contemplar necesariamente acciones tendientes a la regularización de la urbanización ni a la transferencia del dominio.

De esta forma, el caso que analizamos en este trabajo es previo a la masificación de las políticas de regularización en nuestro país y no contó en sus inicios prácticamente con ninguna intervención estatal, por lo que era una regularización dominial "privada", liderada por una organización social de base territorial, y que se valió para ello del marco normativo que regula las relaciones entre privados y los derechos reales, básicamente el Código Civil.

Sólo a partir del proceso que culminó con la sanción de la Ley Provincial 3.396 en 2000 , se empezó a discutir una política de regularización dominial sistemática en la provincia, independientemente de lo que pudieran haber hecho algunos gobiernos locales por su cuenta. Uno de los principales interesados en la implementación de esta operatoria era la Municipalidad de San Carlos de Bariloche (MSCB), donde se calculaban que había más de 10 mil lotes en condiciones irregulares que podrían ser regularizados en ese marco. ${ }^{14}$ No obstante, la Ley Provincial 3.396 nunca fue reglamentada, por lo que su implementación no avanzó durante más de 13 años.

Ya en 2003 la Municipalidad de San Carlos de Bariloche había sancionado la Ordenanza 1283 para adherir al régimen nacional, evidenciando una preocupación por la problemática. La situación habitacional seguía recrudeciendo en la ciudad a lo largo de la década. ${ }^{15}$ El encarecimiento de los precios de los terrenos, su desfasaje con respecto a cualquier nivel de ingreso medios de sectores populares y medios, la falta de acceso a financiamiento y una por lo menos errática política de suelo urbano municipal no hacían más que restringir aún más el acceso al suelo urbano para las mayorías, planteando en los hechos la ocupación como uno de los únicos canales de acceso efectivo.

Si bien todavía en 2013 la implementación de la regularización no había tenido avances 
sustanciales, la discusión impulsada desde fines de la década de 1990 sobre la aplicación de la Ley Pierri en Río Negro y en Bariloche sirvió para visibilizar una problemática que estaba completamente invisibilizada. Uno de los principales barrios que planteó la discusión fue el Barrio Villa Llanquihue, ubicado en el km 23,5 de la Avenida Bustillo. Este barrio popular de origen informal había sido producto de la ocupación progresiva de lotes abandonados por sus propietarios, pese a lo cual habían empezado a emerger amenazas de desalojo por las demandas de algunos titulares registrales. En 2007, la Ordenanza 1704-CM-07 creo el "Programa de Regularización dominial Villa Llanquihue", que constituye un "Paraguas de seguridad Jurídica"16 en relación a la situación dominial del barrio. Este programa contemplaba la declaración de utilidad pública y sujeto a expropiación del conjunto del barrio, como una forma de evitar amenazas de desalojo y garantizar la permanencia de los habitantes, hasta tanto se llevara adelante la efectiva regularización. En septiembre del mismo año fue aprobada la ley Provincial 4237 en la Legislatura de Río Negro, conocida como "Ley Villa Llanquihue".

Al calor del trabajo y las demandas de cierto sector de la población y de su expresión organizada en organizaciones de base se fue conformando un espacio que impulsaba reivindicaciones en materia habitacional y que buscaba incidir en la orientación de las políticas públicas implementadas. Este espacio de carácter informal se conformó en 2006 con la denominación de "Mesa de Organizaciones", donde participaban numerosas expresiones populares, entre otras: el EPT-FGN, Comisión de Tierras del Barrio 10 de Diciembre, Juntas
Vecinales (reconocidas legalmente o no) como Villa Llanquihue, Jamaica, Asociación Civil Norte-Sur, Pastoral Social, Pastoral Carcelaria, Movimiento de Ocupantes e Inquilinos (MOI(TA), la Federación de Tierras y Viviendas, etc. Como parte de este proceso de impulso y discusión se originó gran parte de la normativa existente en la materia, entre otras:

- Creación del Instituto Municipal de Tierras y Viviendas para el Hábitat Social (Ordenanza 1815-CM-2008)

- Creación del Consejo Social de Tierras, como forma institucionalización de la Mesa de Organizaciones (Ordenanza 1595-CM-2006)

- Creación del Banco de Tierras (Ordenanza 1594-CM-2006)

- Declaración de Emergencia Habitacional (Ordenanza 1825-CM-2008).

Incluso, en octubre de 2007 se organizó un Encuentro de Organizaciones de la tierra en la ciudad de San Carlos de Bariloche impulsado por organizaciones de este espacio y se generaron articulaciones e intercambios con organizaciones e instituciones provinciales y nacionales, como el Seminario Instrumentos Jurídicos de Regulación del Suelo en la Ciudad Autónoma de Buenos Aires, realizado en mayo del 2007 en el Anexo Cámara de Diputados de la Nación.

Pero la puesta en marcha de la operatoria de regularización seguía siendo una promesa incumplida. Recién el 29 de noviembre de 2013 se firmó un convenio con el IPPV que habilitaba la implementación descentralizada de la operatoria por parte de la MSCB, como caso excepcional en la provincia. La Resolución municipal 743 de 2014 dispuso la implementación de la operatoria en función del convenio firmado, designando como 
autoridad de aplicación al IMTVHS. Asimismo, afectó a la operatoria a la Escribanía General de Gobierno Municipal, que se encarga de todo el trabajo notarial involucrado. La resolución fijó un rango de inmuebles a ser alcanzado por la operatoria de hasta $\$ 350.000$ de valor fiscal y hasta $1.500 \mathrm{~m}^{2}$ de superficie. Para garantizar el financiamiento de la operatoria, se creaba un Fondo Específico Afectado a la Regularización Dominial "Ley Pierri" y se establecía que para el cómputo de la contribución se tomara un valor fiscal mínimo de $\$ 150.000$ para aquellos inmuebles con valuaciones menores.

Lo central para la implementación de la operatoria es lo que se denomina documentación probatoria. Es decir, es necesario aportar pruebas que certifiquen la ocupación con anterioridad al primero de enero de 2006. Esta documentación puede ser muy diversa: boleto de compraventa, cesión de derechos, recibo de compra de lote, cesión de derechos posesorios, certificados médicos, certificados de registro escolar, certificados de vacunación, etc. Lo central es que tiene que figurar nombre del titular, fecha de emisión del documento y domicilio en el lote que se busca regularizar.

En 2014, finalmente se puso en marcha la operatoria. Al momento de escribir este trabajo se estaban finalizando los primeros expedientes para llevar adelante la confección de las primeras actas-escrituras a ser registradas. A diferencia del caso más conocido de ejecución de la Ley, la Provincia de Buenos Aires, donde requirió de un convenio con el Colegio de Escribano de la Provincia para la conformación de las "Casas de Tierras"; el Municipio de San Carlos de Bariloche optó por crear una Escribanía General de Gobierno Municipal para llevar adelante todo el trabajo notarial involucrado en la operatoria.

El IMTVHS en un principio privilegió otros barrios para iniciar el proceso de regularización (Villa Llanquihue y Nahuel Hue), pero habilitó a aquellos barrios que contaran con organizaciones de base interesadas a participar en una implementación descentralizada. Este fue el caso de Virgen Misionera, donde el EPT junto con la Universidad Nacional de Río Negro, en el marco de un proyecto de extensión avalado por el IMTVHS, conformó un equipo para la aplicación descentralizada de la operatoria que está actualmente en ejecución.

Si bien existe una gran expectativa en términos de que la Ley 24.374 permita saldar de una vez por todas gran parte de la problemática habitacional del barrio, incluso los cálculos más optimistas dan cuenta de que una proporción elevada de los casos no podrán acogerse a este régimen, sea porque algún propietario o derechohabitente se oponga, sea porque por algún motivo no cumpla con los requisitos establecidos por la ley -como la fecha de ocupación, la existencia de documentación que pruebe de manera fehaciente dicha fecha, el tamaño de los lotes, su valuación, etc. De ahí que la problemática habitacional será persistente en este y otros barrios populares en tanto no se rediscuta de manera profunda el contenido y la función del derecho de propiedad. 


\section{Situación actual: conflictos, demandas y posibles respuestas}

La situación actual en Virgen Misionera podría caracterizarse como una "tensa calma", dado que la situación en general es de relativa estabilidad y seguridad en la tenencia de los terrenos. Esto puede observarse en el bajo nivel de menciones que tiene la regularización dominial (papeles de los terrenos) en el mencionado relevamiento de 2011, en pleno reclamo por la implementación de la operatoria de regularización. No obstante, empiezan a haber casos de propietarios, o herederos de propietarios, que reclaman los derechos sobre los lotes. Incluso, existen casos donde los propietarios o herederos pretenden desconocer las negociaciones realizadas en el pasado con intermediación del EPT, amparándose en formalidades legales. En virtud de ello, empiezan a aparecer causas de desalojo por parte de propietarios que quieren recuperar la posesión de los lotes. Existen al menos dos casos avanzados de conflicto en sede judicial que podrían terminar con la restitución de los terrenos a sus titulares registrales, después de años de posesión por parte de sus habitantes. La puesta en marcha de la operatoria de regularización ha renovado las expectativas de dar respuesta definitiva a una vieja demanda, pero no termina de estar claro qué nivel de concreción tendrán estas expectativas.

Dijimos más arriba que desde 2002 los precios de los terrenos no han cesado de subir. No obstante, no hay datos sistemáticos fiables como para realizar un diagnóstico del mercado de suelo urbano y de inmuebles en la ciudad. A modo ilustrativo, puede verse que en algunos de los principales canales de oferta del mercado inmobiliario - Revista $A B C$ Sur - se pueden encontrar oferta de terrenos de entre 800 y $1.000 \mathrm{~m}^{2}$ por un valor de alrededor de 30, 40 o 50 mil dólares en barrios linderos como Rancho Grande, de perfil socioeconómico medio y medio-alto, o incluso dentro mismo del barrio, en aquellas porciones regularizadas. Las propiedades edificadas, por su parte, se ofertan a precios de alrededor de U\$S140.000, dependiendo de la cantidad de metros cubiertos y las características de la construcción. En barrios populares como El Frutillar, ubicado a la vera de la Ruta Nacional 40 - a 6 kilómetros - sobre el eje de expansión sur de la ciudad, un terreno puede costar entre U\$S10 y 20 mil, según las características del mismo, aunque hayan también oferta de terrenos en pesos, que rondan los $\$ 100$ o \$150 por metro cuadrado. Es posible que en el mercado informal lotes de barrios sin regularizar como Nahuel Hue, ubicado a la misma altura de El Frutillar pero del otro lado de la RN40, sean un poco más accesibles, pero conllevan un riesgo importante en materia de seguridad de la tenencia y no cuentan con tendido de red de gas natural.

Por otro lado, la aplicación de la operatoria de regularización dominial en curso no alcanza ni mucho menos a todos los casos. Existen numerosas ocupaciones posteriores a 2006 que quedan excluidos de la operatoria, además de otras situaciones que no pueden ser encuadradas dentro de la ley (ocupación de más de un lote, lotes de superficie elevada, alto valor fiscal del mismo, casos donde no se puede respaldar la posesión con documentación probatoria, 
etc.). Además, la operatoria de regularización no obsta para que en caso de que aparezca oposición por parte del titular de dominio, la misma se frene y se deba resolver el conflicto en sede judicial, con altas probabilidades de terminar en favor del propietario si la posesión no alcanza los veinte años requeridos. La Ley 24.374 sólo establece un procedimiento abreviado y de carácter administrativo para la prescripción adquisitiva del dominio, pero no elimina el dominio del propietario original en el caso de que este comparezca antes de los 10 años, plazo en el cual se perfeccionan las actas-escrituradas labradas en el marco de implementación de la Ley.

En aquellos casos donde los veinte años que establece el código civil para la realización de la usucapión ya se cumplieron no parece haber mayores inconvenientes y difícilmente pueda revertirse la tenencia por parte del ocupante, independientemente de la titularidad del dominio, pero existen muchos casos donde este plazo no se ha cumplido aún. Incluso pudiera darse la situación paradójica de que el movimiento y difusión generado por la implementación de la operatoria, que incluye publicación de edictos y notificaciones al domicilio de los titulares de dominio, genera el efecto indeseado de "avivar" a muchos de los propietarios que estaban completamente olvidados de su propiedad. Esto de hecho es uno de los temores concretos por parte de los habitantes, algunos de los cuales se han negado a iniciar el trámite de regularización por ese motivo. ${ }^{17}$

Existen otras formas de solución de esta problemática que se han intentado en países de la región. En Brasil, por ejemplo, se creó una figura para tratar de resolver este tipo de situaciones que es denominada usucapión especial urbana. Este instrumento establecido en la Constitución de 1988, fue incorporado en la Ley 10.257 conocida como "Estatuto de la Ciudad", promulgada en 2001. Esta ley respondió a la incorporación en la Constitución de 1988 de un capítulo dedicado a la política urbanística, donde se establecían: a) que la política de desarrollo urbanístico tiene por objeto ordenar el pleno desarrollo de las funciones sociales de la ciudad y garantizar el bienestar de sus habitantes; b) la obligatoriedad de un Plan Director para toda localidad mayor a los 20 mil habitantes; c) la función social de la propiedad urbana; d) el parcelamiento y edificación obligatoria en aquellas áreas definidas por el Plan Director; e) la usucapión especial urbana de parcelas de hasta $250 \mathrm{~m} 2$ al cabo de cinco años. Este derecho sólo podía ser otorgado una única vez y para aquellos hogares que no poseyeran otra propiedad.

Este último instrumento fue recogido en el Estatuto de la Ciudad entre los instrumentos de la política urbana (Capítulo II, Sección V). Se preveía la posibilidad de realizar incluso una usucapión colectiva en aquellos casos donde no pudieran ser delimitados con claridad los terrenos ocupados, constituyendo un condominio especial que es indivisible salvo resolución favorable de dos tercios de los condóminos. Las resoluciones relativas a la administración de este condominio especial se tomarán por simple mayoría. Asimismo, se habilitaba la sumatoria de posesiones con el poseedor anterior mientras éstas fueran continuas.

La usucapión especial urbana supera la visión civilista del derecho de propiedad, 
que lo consideraba absoluto e ilimitado, perpetuo y exclusivo. Esto implicaba que tenía el derecho de no usar, no gozar y no disponer de su propiedad, generando una carga sobre el conjunto de la comunidad y el Estado.

Otro de los instrumentos de la política urbana fijados en el Estatuto de la Ciudad, orientado a la regularización de la tenencia del suelo urbano, es la creación de Zonas Especiales de Interés Social (ZEIS). Las Zeis fueron creadas por la Ley Prezeis de 1987, modificada en 1995 y 1997. Sin embargo, la evidencia en Brasil es contradictoria sobre la utilización de este instrumento, porque según algunos autores la declaración de una ZEIS no modifica la tenencia, ni modifica la percepción de la seguridad de la tenencia (De Souza y Zetter, 2004). Si bien los Zeis fueron importantes para eliminar el riesgo de desalojo de las ocupaciones, la definición de Zeis sirvió para la introducción de mecanismos del mercado formal en los asentamientos, generando desplazamientos de la población más vulnerable, al generarse expectativas de una ulterior legalización de la tenencia.

Pese a la diversidad de instrumentos y experiencias, el acceso al suelo urbano y la seguridad de la tenencia son cuestiones todavía pendientes en los países de nuestra región, lo que redunda en una permanente - y cada vez mayor - conflictividad social. Esta situación pone de manifiesto las limitaciones de las políticas de regularización implementadas y la necesidad de replantear los alcances y el contenido del derecho de propiedad. Pareciera que no existe política de regularización que sea suficiente en un contexto general de restricción de acceso al suelo urbano, porque la irregularidad vuelve a generarse de manera permanente, por la misma dinámica del hábitat popular. El problema no es tanto registral, de titularidad de dominio, sino de seguridad de la tenencia. Es una cuestión de entender el suelo urbano en su faz de bien de uso antes que bien de cambio o patrimonial.

El centro del problema tiene que ver con la concepción patrimonialista que nutre nuestro ordenamiento jurídico, que interpreta al derecho de propiedad como un derecho inviolable y perpetuo, sin importar la conducta del titular del dominio, es decir, sus obligaciones y no sólo sus derechos. Esta concepción patrimonialista desconoce de manera flagrante la renuncia o el descuido por parte de muchos propietarios con respeto a su propiedad urbana, lo que genera múltiples inconvenientes de tipo urbanístico, económico y social para el conjunto de la sociedad. Esto configura un acto de abandono por parte del propietario que debe ser tomado como causal de extinción de dominio, para permitir la recuperación de estos terrenos abandonados para el patrimonio del Estado, como se desarrolla en Paolinelli, Guevara y Oglietti (2014).

El abandono puede, o debiera, ser considerado un uso abusivo del derecho de propiedad, por lo que es causal de extinción del dominio, sin requerir mayores operatorias o acciones de regularización para el saneamiento del dominio. El artículo 2607 $\mathrm{CC}^{18}$ establece que el dominio se pierde por abandono, aunque otro aún no se la hubiere apropiado. Aunque otras normas del mismo código dan la idea de que el dominio es perpetuo, independientemente del ejercicio que se realice de esto, mantener la ficción de una "propiedad sin propietario" acarrea perjuicios que la hacen incompatible con el valor de justicia que debe ordenar y orientar 
la actuación de la realización colectiva de la comunidad (Paolinelli, Guevara y Oglietti, 2014). Esto se debe a que el abandono determina el incumplimiento de la función social de la propiedad, incorporado a nuestro ordenamiento jurídico a través de tratados internacionales con rango constitucional desde la reforma de $1994 .{ }^{19}$ Extinguido el dominio por abandono, queda allanado el camino para que el Estado adquiera la propiedad del inmueble en virtud de su dominio eminente sobre todas las cosas que se encuentran situadas dentro de los límites territoriales de la República que carecen de dueño, en nuestro caso, en virtud del abandono del propietario. Posteriormente, se podría proceder a transferir los terrenos a nombre de los ocupantes para regularizar la tenencia de forma definitiva, ceder el uso en comodato individual o colectivo, o cualquier otra forma de asegurar la tenencia del suelo para el desarrollo del hábitat en condiciones dignas, eliminando toda la conflictividad y burocracia involucrada en las políticas de regularización. Este criterio y no otro está en la base por ejemplo de la utilización de la prescripción administrativa, establecida por la Ley 24.320, en la Provincia de Buenos Aires para la regularización de asentamientos informales (Scattolini, 2011). Para ello, se procedió a disponer la cesión de los derechos posesorios de los ocupantes en favor del Estado, que posteriormente inscribe los inmuebles y los vuelve a transferir hacia sus ocupantes. No obstante, este mismo instrumento podría utilizarse para anticiparse a la conformación de los asentamientos, de manera que el Estado pudiera incorporar tierras para generar una política de acceso al suelo urbano de forma sostenida.
Tanto la extinción del dominio por abandono como la prescripción administrativa son instrumentos que no estuvieron originalmente pensados para la regularización de la tenencia en barrios populares de origen informal, sino que su origen está vinculado a las obras de infraestructura civil por parte del Estado, como caminos, escuelas y otras. La falta de instrumentos adecuados para atacar la informalidad urbana, ya que los existentes fijan plazos demasiado largos y costos superiores a los que puede afrontar en general un hogar de ingresos bajos, hacen que las alternativas disponibles no sean aplicables en la mayoría de los casos y los procesos de regularización terminen naufragando, como suele ocurrir con los juicios de usucapión.

Creemos que existe evidencia suficiente por parte de la investigación académica y de la implementación de políticas públicas en materia de regularización de barrios populares de origen informal, para reclamar una reformulación del alcance y el contenido del derecho de propiedad del suelo urbano y de los inmuebles, en virtud de garantizar el cumplimiento de la función social de la propiedad y el derecho a la ciudad para los sectores populares.

\section{Conclusiones}

Este artículo presentó resultados preliminares de un trabajo de investigación en curso sobre políticas habitacionales y urbanas en San Carlos de Bariloche. Se caracterizó el proceso de urbanización de la ciudad, que presenta algunos rasgos comunes con otras ciudades de 
perfil turístico, especialmente aquellas donde el atractivo se basa en el medio ambiente privilegiado, entre otros la fuerte incidencia de la especulación inmobiliaria, la excesiva expansión suburbana resultante y la presencia de un stock importante de propiedades abandonadas por sus propietarios que fueron progresivamente ocupadas.

En este marco, se reconstruyó el proceso de regularización del barrio popular de origen informal Virgen Misionera, ubicado a 7,5 kilómetros del centro de la ciudad, sobre la ladera del cerro Otto. El poblamiento data de más de 60 años, por lo que los habitantes están arraigados en el lugar y el barrio está completamente consolidado, pero todavía persisten problemas y conflictos vinculados a la titularidad de las tierras con los propietarios originales y emergen conflictos vinculados a la consolidación del barrio.

Desde mediados de la década de 1980, gracias al trabajo del cura Curulef y la Fundación Gente Nueva se impulsó un proceso de regularización progresiva, pero que todavía hoy está inconcluso. Recientemente se está implementando la Ley 24.374 en la ciudad y en el barrio, pero existen numerosos casos que no pueden ser encuadrados en el marco de dicha ley. También emergieron nuevos conflictos vinculados a la consolidación y densificación del barrio.

La situación actual en Virgen Misionera podría caracterizarse como una "tensa calma", dado que la situación en general es de relativa estabilidad y seguridad en la tenencia de los terrenos. La relativa abundancia de tierra de expansión en la ciudad y el abandono por parte de los propietarios permitió durante años que los procesos de regularización pudieran avanzar de forma más o menos exitosa. No obstante, en un contexto donde los precios de los terrenos se dispararon en los últimos quince años y se recrudecieron los conflictos por el acceso a la tierra, el artículo reflexionó sobre los límites de las estrategias de regularización utilizadas en nuestro país que parecen ser insuficientes como muestra la experiencia de Virgen Misionera. Asimismo, se planteó la necesidad de reformular el contenido y el alcance del derecho de propiedad para dar respuesta definitiva a las problemáticas del acceso y la tenencia segura, poniendo de relieve la función social de la propiedad y las obligaciones de los propietarios.

\section{Tomás Alejandro Guevara}

Universidad Nacional de Río Negro, Sede Andina, Centro Interdisciplinario de Estudios sobre Territorio Economía y Sociedad. San Carlos de Bariloche/Río Negro, Argentina.

tguevara@unrn.edu.ar 


\section{Notas}

(1) La ciudad de Bariloche es una localidad fuertemente determinada por el sector turístico (Méndez, 2010), independientemente de contar un importante sector de administración pública y un pujante sector de economía popular. En 2006, más de la mitad (51,3\%) de su PBG fue generado por el sector turístico y actividades conexas (Monasterio 2006), mientras que el "complejo turístico" representaba en 2005 más del 45\% de los empleos totales Abaleron (2007).

(2) Se encontraron numerosos testimonios de folletería espuria en estas subastas masivas, donde se comercializaban localizaciones que no se correspondían con la ubicación real de los lotes.

(3) Remitimos para una mirada histórica a Agüero (2007).

(4) Entrevista con Gustavo Gennuso, miembro original del Equipo Pastoral de Tierras, realizada en febrero de 2013.

(5) Una situación similar se puede encontrar con el Barrio Parque Villa Llanquihue o Don Bosco con la Junta Vecinal Llao-Llao, por ejemplo.

(6) Al momento de empezar a escribir este artículo se conoció la noticia del fallecimiento de Curulef, después de una larga enfermedad.

(7) En el año 1982 se fundó la Escuela Virgen Misionera, en el año 1985 nace el Taller Mugica y en 1987 se inaugura el Jardín Arco Iris, todo en el barrio. Asimismo, en el año 1989 nace el Secundario Amuyén. La experiencia educativa lleva a la Fundación a trabajar más tarde en el Barrio 2 de Abril (34 Hectáreas), donde en 1994 comienza a funcionar el Taller de Capacitación Angelelli y un año después el Jardín Mundo Nuevo. En el 2000 se crea el secundario para adultos Jaime de Nevares funcionando en dependencias del Colegio Amuyén y se inaugura también la Escuela primaria Nuestra señora de la Vida. Finalmente, en 2008 empezó a funcionar la Escuela Técnica Nehuen Peuman. La Fundación Gente Nueva es una de las organizaciones más grandes del país en materia de gestión social educativa.

(8) Al respecto decía Monseñor Hesayne en su Exhortación Pastoral Postsinodal:

(9) "Se trata de evangelizar a todo el hombre rionegrino y a todos los hombres rionegrinos. Vale decir que la acción evangelizadora ha de llegar a la totalidad de cada una de las personas individuales y a la totalidad del pueblo de nuestra provincia: al corazón de cada hombre y mujer, a la cultura de nuestro pueblo y a sus estructuras y ambientes sociales."

"2.2. Tengamos en cuenta, en primer lugar, a los dueños primitivos de nuestro suelo, a la "gente de la tierra", los mapuches, dominados, avasallados, despreciados y oprimidos por el "huinca", el blanco cristiano. (...). Digamos lo mismo acerca de sus numerosos descendientes que pueblan los barrios marginados de nuestras ciudades, desarraigados de su terruño y de sus costumbres. "2.3. Una buena parte de la mano de obra en la Patagonia la constituyen desde hace tiempo muchos hermanos chilenos, que siguen cruzando la frontera en número considerable, apremiados por la realidad socio-económico-política del país. Tenemos para con ellos un especial deber de fraternidad y de hospitalidad".

"5.3. En consecuencia, la primera instancia en nuestra acción evangelizadora es reconocer la pobreza-miseria concreta en Río Negro: el hambre y falta de vivienda de muchas familias; la desocupación y marginación de muchos trabajadores; la opresión en que subsisten los aborígenes, primeros dueños de esta tierra patagónica; los peones de chacras y campos desprotegidos socialmente; los trabajadores golondrinas; los migrantes, especialmente chilenos; los pobladores de barrios periféricos, centros suburbanos y zonas rurales. 
Los pobres no son una abstracción, tienen nombre y apellido y son víctimas de situaciones y estructuras injustas que debemos superar. Con esos pobres, entonces tendremos que identificamos para ser la Iglesia de Jesucristo, sin olvidar, por supuesto, a los enfermos y moribundos, ancianos y presos, que sufren otra forma de pobreza."

“5.5. En las propuestas de nuestro Sínodo aparece clara y reiteradamente la necesidad de la presencia de la Iglesia en los barrios más pobres, en las zonas marginadas, la necesidad de pensar la evangelización no desde el centro sino desde la periferia, la necesidad de estructurar la Iglesia desde los valores de los pobres, compartiendo sus problemas, alegrías y esperanzas, lejos de paternalismos o beneficencias. Para más de uno de nosotros eso significará morir a nosotros mismos, a nuestros esquemas "clasistas", para elevarnos a la dignidad humana de hijos de Dios y capacitarnos, en todos los órdenes de la vida, como miembros activos de la Iglesia."

“5.10. "Desde los pobres a todos" no es simplemente una estrategia pastoral. Es la dirección existencial tomada por Jesucristo en su peregrinaje histórico. Para nosotros, es la única forma en que podemos captar el plan de Dios y ser fieles a él. Puestos en oración sincera ante Dios, personal y comunitariamente, decidiremos qué tenemos que hacer como individuos o instituciones, en orden a una vida cristiana auténtica, con relación al uso o renuncia de bienes materiales, y con relación a compromisos políticos o búsqueda de alternativas sociales realmente evangélicas.

"Desde los pobres a todos" no es nada más ni nada menos que el camino para lograrnos como Iglesia pobre, desprovista de medios de poder humano contando en forma ilimitada con la fuerza de Jesús Resucitado; lugar de comunión visible, mediante verdadera participación de bienes y personas; camino de gozo y esperanza de un mundo rionegrino más justo y fraterno, para gloria de Dios bendito."

"6.1. No hay vida cristiana sin comunidad. Sólo en comunidad podemos escuchar, acoger y anunciar a Jesucristo. Ella nos permite lograr concretamente la comunión eclesial y constituirnos así en un signo positivo de que han germinado en el corazón humano los valores del Reino: del Reino que Jesús anuncia luchando contra la opresión, la injusticia, la marginación y discriminación de cualquier tipo, como testimonio de una real "comunión" con Dios y los hombres."

(9) La Junta Vecinal se encuentra recaudando fondos mensualmente para la realización de este proyecto, para lo cual se hizo un presentación para pedir financiamiento a un organismo de nivel nacional.

(10) Entrevista con integrante original del grupo pastoral de Curulef y miembro fundador de la Fundación Gente Nueva, realizada en octubre de 2014.

(11) Estos datos surgen de la sistematización que se hizo de los archivos y documentos del EPT en el marco de un proyecto de extensión co-financiado por la SPU y la UNRN, que dirige el autor, titulado "Alternativas de resolución de conflicto vinculado al hábitat: asociativismo y regularización".

(12) Se recuperan en esta sección elementos de Di Virgilio, Arqueros y Guevara (2012)

(13) Artículos 75 inc. 17, 41 y 43.

(14) Este número sale de estimaciones informales, no hay datos oficiales, por parte de funcionarios del Instituto Municipal de Tierras y Viviendas para el Hábitat Social en el año 2012, cuando parecía inminente la puesta en marcha de la operatoria.

(15) En 2006 se había producido la toma masiva de más de 2.000 lotes que dio origen al actual barrio de Nahuel Hue, en la zona denominada Pampa de Huenuleo. 
(16) Según la expresión de uno de los técnicos involucrados en su formulación

(17) Coherentes con su visión sobre el accionar de la anterior conducción de la Junta Vecinal Virgen Misionera, algunos miembros del EPT achacan a los ex integrante de la comisión, el haberse contactado con dueño antiguos en virtud del inicio de la implementación de la operatoria de regularización.

(18) Esta numeración se corresponde con el viejo Código Civil, que fue reemplazado recientemente, pero con posterioridad a la elaboración de este artículo, por un nuevo Código Civil y Comercial, sin mayores novedades relativas a los derechos reales. Pese al reclamo de diversos sectores, no se incorporó al nuevo código la reglamentación de la función social de la propiedad incorporada por tratados internacionales como el Pacto Internacional de Derechos Económicos, Sociales y Culturales. De esta manera, el vacío legal sobre cuáles son los alcances del derecho de propiedad habrá de mantenerse en el tiempo, alentando la interpretación hegemónica sobre el alcance ilimitada de este derecho y generando una innecesaria conflictividad social en aras de mantener una ficción jurídica inconducente.

(19) En estos días se está por sancionar en el Congreso de la Nación una nueva versión unificada de los Códigos Civil y Comercial. Si bien existieron numeroso pronunciamientos por parte de organizaciones e instituciones por la incorporación explícita de la función social de la propiedad, entre otras cuestiones relevantes relativas al hábitat, el pedido no encontró eco en los legisladores.

\section{Referências}

ABALERON, C. A. (2001). The Pros and Cons of Peri-Urban Management in a Tourist City. In: DPU INTERNATIONAL CONFERENCE: RURAL-URBAN ENCOUNTERS: MANAGING THE ENVIRONMENT OF THE PERI-URBAN INTERFACE. Londres.

(2007). Documento de la base territorial de San Carlos de Bariloche. Ministerio de Trabajo y Seguridad Social, Bariloche.

AGÜERO, A. (2007). "Somos de acá". In: FUENTES, R. y NúÑEZ, P. (2007). Sectores populares: identidad cultural e historia en Bariloche. Tomo I. Bariloche, Núcleo Patagónico.

AVILA, P. (2013). Regularización de la tenencia del suelo urbano en Brasil: Avances recientes y desafíos. Journal Ciencias Sociales, año 1, n. 1.

CURULEF, J. (c. 1992). La tierra, un bien de todos. Encuadre eclesial. Mimeo.

DE SOTO, H.; GHERSI, E. y GHIBELLINI, M. (1986). El otro sendero: la revolución informal. Lima, El Barranco.

DE SOUZA, F. y ZETTER, R. (2004). “Urban land tenure in Brazil: from centralized state intervention to market processes of housing land delivery". In: HAMZA, M. y ZETTER, R. (eds.). Market economy and urban change: impacts in the developing world. Londres, Earthscan. 
DI VIRGILIO, M. M. (2011). Participación social y organizaciones sociales en la implementación de políticas orientadas a la producción social del hábitat en el Área Metropolitana de Buenos Aires. Revista S.A.A.P. Buenos Aires, v. 6, p. 11.

DI VIRGILIO, M. M.; ARQUEROS, S. y GUEVARA, T. (2011). Veinte años no es nada. Procesos de regularización en villas y asentamientos informales en la Región Metropolitana de Buenos Aires. Revista Ciudad y Territorio. Madri, n. 167, pp. 109-129.

(2012). Conflictos urbanos en los procesos de regularización de Villas y Asentamientos informales en la Región Metropolitana de Buenos Aires. Revista Urban. Madri, n. 4.

GUEVARA, T. y NÚÑEZ, P. (2014). La ciudad en disputa. Economía y Territorio en San Carlos de Bariloche. Revista Diálogo Andino. Aprobado para su publicación en 2015.

HERZER, H.; GIL, L. y DE ANSO (2012). “Introducción”. In: HERZER, H. (org.). Barrios al sur. Renovación y pobreza en la ciudad de Buenos Aires. Buenos Aires, Café de las Ciudades.

MÉNDEZ, L. (2010). Estado, frontera y turismo. Historia de San Carlos de Bariloche. Buenos Aires, Prometeo.

MONASTERIO, H. (2006). Medición de la economía formal de San Carlos de Bariloche. Estimación del PBI 2006. Universidad Fasta, Inédito.

NÚÑEZ, P. y GUEVARA, T. (2014). La frontera argentino-chilena y la pertenencia social. San Carlos de Bariloche, 1966-1983. Revista Austral de Cs. Sociales. En evaluación.

PAOLINELLI, J.; GUEVARA, T. y OGLIETTI, G. (2014). Impuesto a los bienes urbanos ociosos. Una herramienta tributaria contra la especulación inmobiliaria y al servicio de la planificación. Buenos Aires, Café de las Ciudades.

PÉREZ, S. (2004). Identidades urbanas y relocalización de la pobreza. Revista Intersecciones en Antropología. Olavarría, Universidad del Centro de la Prov. de Buenos Aires.

SCTATOLINI, J. L. (2011). La prescripción administrativa: hacia la función social de la propiedad. Revista RAP Digital, n. 100-102.

WARD, P.; JIMÉNEZ HUERTA, M. E.; GRAJEDA, E. y UBALDO VELÁZQUEZ, C. (2011). Self-help housing policies for second generation inheritance and succession of 'The House that Mum \& Dad Built'. Habitat International, n. 35, pp. 467-485.

Texto recebido em 31/maio/2015

Texto aprovado em 11/set/2015 